\title{
INDÚSTRIA CULTURAL, MÍDIA E EDUCAÇÃO: IMPLICAÇÕES NA FORMAÇÃO DO PENSAMENTO INFANTIL
}

\author{
Adna Tamires Gordiano Valente (Pedagogia - UEL) \\ Profa. Dra. Marta Regina Furlan de Oliveira (orientador) \\ marta.furlan@yahoo.com.br
}

\section{RESUMO}

Este texto tem o objetivo de refletir acerca dos conceitos de indústria cultural, mídia e consumo, tecendo reflexões sobre seus impactos na formação do pensamento infantil. $\mathrm{O}$ estudo é fruto das reflexões relacionadas ao Projeto de Pesquisa - "Indústria Cultural, Educação e Trabalho Docente na Primeira Infância: da semiformação à emancipação humana" da Universidade Estadual de Londrina e, ainda, das atividades de Iniciação Científica - CNPQ/UEL. A metodologia dispõe de leituras e estudos em autores como T. Adorno e M. Horkheimer (1985), H. Marcuse (1973) entre outros. Percebe-se, contudo, que a indústria cultural e a cultura midiática torna-se impactante na vida das crianças de diversas formas, seja pela suas brincadeiras, comportamentos, alimentação, vestuário, lazer etc. Hoje os vídeo games, a TV, computador, ou seja, os brinquedos espetaculosos da indústria cultural ocupam o espaço das atividades consideradas significativas, promovendo diversas consequências negativas na criança e na infância. Diante disso, a escola infantil e o professor tem um papel fundamental como mediador do conhecimento e da formação do pensamento, mediando momentos que são significativos para o aprendizado infantil e, possibilitando as crianças novas experiências pedagógicas que vão além do consumo, da mercadoria e dos padrões midiáticos.

Palavras-Chave: Mídia. Educação. Infância.

\section{INTRODUÇÃO}

Este texto tem o objetivo de refletir acerca dos conceitos de indústria cultural, mídia e consumo, tecendo reflexões sobre seus impactos na formação do pensamento infantil a partir dos estudos de Iniciação Científica/ Bolsa CNPQ 2015-2016 e das reflexões no Projeto de Pesquisa - "Indústria Cultural, Educação e Trabalho Docente na Primeira Infância: da semiformação à emancipação humana" da UEL/CNPQ.

Como metodologia de trabalho e estudo, em primeiro momento, analisaremos a indústria cultural e seus impactos sociais, alargados com os conceitos sobre mídia e consumo. No segundo momento, faremos uma reflexão mais pontual desses impactos na formação do pensamento infantil, principalmente, considerando como a criança reage a esses mecanismos sedutores do consumo na sua vida social e nos seus momentos lúdicos, como o brincar. Essas reflexões são urgentes e necessárias para pensarmos em novos direcionamentos pedagógicos voltados ao trabalho com a criança e com a formação do pensamento infantil.

Considerando os impactos da indústria cultural, mídia e consumo, partimos do pressuposto teórico-filosófico de que essas temáticas tem sido significativamente sendo 


\section{SEMINÁRIO DE PESQUISA EM CIÊNCIAS HUMANAS - SEPECH \\ Humanidades, Estado e desafios didático-científicos \\ Londrina, 27 a 29 de julho de 2016}

discutidas e refletidas no contexto da sociedade contemporânea, haja vista, seus impactos diretos na vida social e educativa dos sujeitos. Nesse sentido, Theodor Adorno e Max Horkheimer (1985) à luz dos fundamentos da Teoria Crítica ${ }^{1}$, trazem contribuições fundamentais para compreendermos esse processo industrial e mercadológico, uma vez que segundo os autores, a indústria cultural trata-se de um mercado do conhecimento, da cultura, da aquisição de valores, na qual tudo se torna mercadoria e consumo. Um de seus aspectos é a reprodutividade da arte, da cultural e do conhecimento em formato de padronização, uniformização e adaptação social. Nesse sentido, os bens culturais passam a existir para que todas as pessoas se apropriem como forma de lazer, prazer e espetáculo; distanciando do que deva ser o processo de conhecimento e formação humana.

A indústria cultural faz parte de um conjunto de ideologia. Como afirmam Maia e Oliveira (2015), a indústria cultural tem seu papel ideológico e sedutor na sociedade, em que tudo tem seu preço, onde a mercadoria e os bens de consumo prevalecem na relação entre seres humanos. Para Adorno e Horkheimer o termo Industria cultural é um sistema político e econômico, no qual a mídia, os livros e as músicas são usados como um "controle" social, que dita o modelo de vida para os indivíduos à luz da mercadoria e da razão instrumental, ou seja, é praticamente uma ideologia de mercado que acaba sendo imposta as pessoas, deixando de lado a valorização da cultura.

A Indústria Cultural cria mecanismos de sedução e fetiche, atraindo pessoas (adultos, crianças, idosos) para o processo de adaptação e conformação ao produto, ou seja, a mercadoria. Nesse sentido, fortalece o pensamento no indivíduo de que este não precisa ser um artista, basta apenas adquirir pelo consumo a obra de arte, garantindo-lhe status e posição social. Essa adaptação do indivíduo a mercadoria possibilita lucros financeiras e fortalece o sistema capitalista. Furlan afirma que: "Em uma sociedade excludente, individualista e desigual, consumir tornou-se uma forma particular de modo ativo, como também uma maneira de ordenar os desejos que podem ser concretizados em alguns objetos" (OLIVEIRA 2013, p. 24842).

Nesse processo de conformação ao objeto/mercadoria, a Indústria Cultural reverte a arte enquanto cultura em objeto meramente mercadológico, expropriando sua autenticidade enquanto arte, criação e conhecimento. Pelo consumo, a arte é reproduzida perdendo seu valor enquanto manifestação artística, tornando-se mais um produto a ser consumido. Nesse enfoque Adorno (1985) contribui ao analisar criticamente acerca do material artístico que vem sendo propagado com fins comerciais, reduzindo-se ao mero conceito de arte-entretenimento, arte-lazer, arte-espetáculo. Acrescenta o autor que a arte só pode ser abarcada num dimensão social, daí sua denúncia ao caráter de manipulação do capital na arte. Afirma ainda que crítica social e crítica artística não podem se separar quando o assunto é a consciência das pessoas. "A priori, antes de suas obras, a arte é uma crítica da feroz seriedade que a realidade impõe sobre os seres humanos" (ADORNO, 2001, p. 13)

\footnotetext{
${ }^{1}$ Chama-se atenção para os escritos de Horkheimer e Adorno, que escreveram o livro "Dialética do Esclarecimento", que foi publicado em 1947. A obra é umas das mais importantes que retrata o cenário da discussão da teoria critica. No capitulo denominado "O Iluminismo como mistificação das massas" é citada pela primeira vez o termo Indústria cultural. Segundo Maia e Oliveira (2015). Os autores relatam que na passagem do século XX é que se constata o caos cultural, e os meios de comunicação em massa como cinema, o rádio e as revistas são apontados aparato que formam a indústria cultural.
} 


\section{SEMINÁRIO DE PESQUISA EM CIÊNCIAS HUMANAS - SEPECH \\ Humanidades, Estado e desafios didático-científicos \\ Londrina, 27 a 29 de julho de 2016}

A mídia aliada a indústria cultural contribui com a divulgação e disseminação de ideologias e, consequentemente, com o conformismo nas pessoas, em todos os níveis socioeconômicos. Uma situação cotidiana pode ser descrita sobre essa questão: Após um dia "duro" de trabalho e estresse, a televisão se encarrega de dar o brilho e distrair o telespectador no final do dia, porém é apresentada uma falsa realidade, desviando seus olhares para questões menos importantes, já que a mídia se resume em vender suas mercadorias e transformar as pessoas em consumidoras incessantes. Pode-se dizer que o tempo livre que o indivíduo passa em frente à televisão está "sendo ocupado pela indústria cultural" (MAIA e OLIVEIRA, 2015 p. 586). Um modelo de vida é ditado pela mídia e vários produtos são apresentados a ele para induzi-lo a consumo e de certa forma ter o controle social.

A indústria Cultural nos faz pensar que somos importante, "popular", criando produtos que parece que se importa em fazer o indivíduo feliz. Neste sentido cria nas pessoas um sentimento de que não se pode viver sem aqueles determinados produtos que os fazem "felizes". As crianças são alvo dessa indústria, as empresas disputam para ganhar sua preferência, com produtos feitos exclusivamente para roubar sua atenção do que é necessário para a vida humana. Para algumas empresas e mercados, as crianças são chamadas de "agência de consumo", gerando altíssimos lucros em mercadorias e produtos relacionados aos alimentos, diversão, vestimentas e ludicidade. Linn (2006) chega a afirmar que é percebível o grande interesse das indústrias comparativas atraindo atenção mais ainda dos especialistas em marketing, para criar desde alimentos a carros, a fim de despertar o interesse desse público infantil.

Acreditamos que, os adultos tem a capacidade de "escolher" o que consomem diferente das crianças que são mais frágeis a ação do marketing, no entanto, nem sempre essa ideia é verdadeira. Existem situações em que os adultos acabam sendo mais influenciados que as próprias crianças. Não são todas as crianças que sabe distinguir um comercial de uma propaganda normal de televisão, deixando-as vulneráveis, pois não compreendem o real interesse da publicidade, que pensou em todos os detalhes para crianças e adultos atraídos para comprar.

Mesmo as crianças que já tem parte da consciência da verdadeira intenção das propagandas e sabe que quase nada que passa em uma propaganda é real, quando é questionada sob um produto pauta-se nas informações que viu nas propagandas e não nas suas experiências próprias de uso. Sendo assim, há uma tendência as crianças serem mais afetadas pelas propagandas do que os adultos, pois agradam as emoções e não o intelecto. A criatividade, a originalidade e integridade são conceitos importantes na vida de uma criança, que merecem ser preservados, porém na maioria das vezes são esmagados pela indústria cultural.

\section{INDÚSTRIA CULTURAL, INFÂNCIA LÚDICA E BRINCAR TECNOLÓGICO}

A experiência do brincar está relacionada a criatividade, ao fato de ter uma infância sadia, na qual é permitido o pensamento imaginativo, criativo e simbólico, sendo fundamental o cultivo de valores humanos e morais, o desenvolvimento da corporeidade e do pensamento cognitivo. O brinquedo que uma criança brinca é 


\section{SEMINÁRIO DE PESQUISA EM CIÊNCIAS HUMANAS - SEPECH \\ Humanidades, Estado e desafios didático-científicos \\ Londrina, 27 a 29 de julho de 2016}

importante para desenvolver sua criatividade, tal objeto pode virar vários outras coisas em sua imaginação, pelo pensamento inventivo.

O brincar, o faz de conta é uma necessidade lúdica, inerente do ser humano, é uma etapa que não pode ser deixada para traz, pois ela tem um significado muito importante para a aprendizagem e desenvolvimento da criança. Infelizmente o brincar está servindo para suprir as necessidades das várias redes de indústrias de brinquedos e não está sendo vista como necessidade do indivíduo. A Diretrizes Curriculares Nacionais para a Educação Infantil (2010), define criança como:

Sujeito histórico e de direitos que, nas interações, relações e práticas cotidianas que vivencia, constrói sua identidade pessoal e coletiva, brinca, imagina, fantasia, deseja, aprende, observa, experimenta, narra, questiona e constrói sentidos sobre a natureza e a sociedade, produzindo cultura.

Entende-se que o brincar é uma das particularidades da criança além de uma necessidade. Todas tem o direito de desenvolver todas essas particularidades por completo, porém a mídia á trabalho da indústria cultural, vem negando esse direito ao indivíduo.

A mídia invade o cotidiano da crianças, para elas é desconhecido um mundo sem a influência da televisão, da propaganda, do telefone, etc. Toda essa influência, tem grande reflexão na sua formação social. Com os brinquedos que a mídia lança, como uma história predeterminada, com tantos programas criados para chamar atenção desse público com o propósito final de vender algo para tal, tudo isso dificulta na construção de sua identidade pessoal e coletiva, além de limitar a imaginação, o brincar, a fantasiar, etc.

Por muito tempo os brinquedos e jogos foram passados de geração a geração, construídos com materiais alternativos e criatividade. Atualmente esses brinquedos foram esquecidos e substituídos por outros que muda a experiência lúdica da criança, claro que com novas formas de criação e estética, entretanto, não favorece a criança o brincar criativo e inventivo, já que todos esses artefatos lúdicos são homogeneizados e padronizados pelo consumo. Esses brinquedos se movimentam, produzem sons, são controlados por controles remotos, sendo assim o individuo não precisa imaginar um avião voando e sair correndo com o brinquedo, ele sem sair do lugar apenas com um controle consegue controlar seu brinquedo, além de desenvolver experiências lúdicas solitárias. A interação com o outro e deixada de lado, a maior parte dos brinquedos são feitos para brincar individualmente.

Linn (2006 p.97) afirma que "devido o fato de as crianças brincarem para entender o mundo, os brinquedos que lhe damos servem de lições e reflexões sobre valores da sociedade"; impactando significativamente na formação do pensamento e na vida da criança de maneira integral. Podemos utilizar como exemplo a boneca clássica chamada Barbie, que transmite a imagem estereotipada de meninas, como estereótipos femininos: magras, altas, ricas e consumidoras, que dita as regras do consumo e define os padrões de beleza; excluindo os que não são adequados a esse padrão de mercado. Ainda, o próprio brincar foi sendo alterado em sua representação, o que antes era destinada a experiência da maternidade em situações de faz de conta, atualmente vivese, no brincar, a preparação para a vida adulta, rodeada de luxo e sensualidade feminina. 


\section{SEMINÁRIO DE PESQUISA EM CIÊNCIAS HUMANAS - SEPECH \\ Humanidades, Estado e desafios didático-científicos \\ Londrina, 27 a 29 de julho de 2016}

No mesmo caminho do consumo, está o jogo eletrônico que se encaixa no padrão da indústria cultural. Por meio da cultura e do lazer garantindo cada vez mais lucros aos mercados e indústrias da diversão e do lazer.

Entretanto, na arena do consumo, o brincar não escapa do impacto da indústria cultural, sendo a criança considerada a alma do negócio, já que mais da metade dos gastos em uma casa é em torno de uma criança. Os brinquedos tecnológicos tornam-se atração do público infantil ampliando cada vez mais a relação entre brinquedo e consumo.

Zanolla (2007) chama atenção a uma necessidade de ser realizados estudos mais aprofundados sobre os jogos eletrônicos, na busca pela compreensão dos aspectos subjetivos relacionados ao fenômeno da identificação das crianças com a violência no vídeo game, e até mesmo as relações de proximidade da criança com os personagens dos games.

Os jogos eletrônicos como elemento de cultura e lazer vão se modernizando, vão sendo desenvolvidos de acordo com os interesses do mercado, sem respeitar o amadurecimento cognitivo, social e moral da criança. Essas empresas geram milhões para "prender" a atenção de crianças e, até mesmo de adultos, por horas. Preocupados em manter sempre novidades no mercado, há uma busca incessante em novos modelos que atenda ao mercado consumidor. Não é diferente com os filmes que chegam as salas dos cinemas e ganham a preferência do público, sendo sequencialmente produzido em formato de jogo eletrônico. É preciso cuidado minucioso por parte dos pais, uma vez que o vídeo game e outros brinquedos tecnológicos vem sendo usados como "moeda" de troca na relação entre pais e filhos, para que as crianças façam determinadas atividades, ou até mesmo para compensar sua ausência.

As influências da indústria cultural são impactantes na vida de crianças e adultos e o preço disso é muito caro, considerando algumas consequências percebidas nesse cenário consumista: crianças solitárias, ausência de relação entre pais e filhos, ter o brinquedo vale mais que brincar, dependência tecnológica, fragilidades humanas, etc. Exemplo disso, é o caso da criança que precisa ter "tal" brinquedo para ser feliz apelando emocionalmente para que seus pais se convençam em comprar o brinquedo, $o$ que na maioria dos casos, os pais acabam cedendo pela própria fragilidade na relação familiar, como as ausências constantes de pais que passam maior tempo longe dos filhos.

\section{A CRIANÇA E O BRINCAR FAST FOOD}

Segundo Linn, (2006) as publicidades de brinquedos juntamente com anúncios de alimentos representam grande parte do marketing infantil. A ligação entre mídia e fabricantes de alimentos é outra estratégia de venda. Cada filme lançado ou livro é lançado também um aparato de produtos, como camisetas, bonecos, etc. As empresas de alimentos não ficam a margem e aproveitam para lucrar também e lançam tais produtos acompanhados com os alimentos. Promoções são feita que na compra de um determinado alimento a criança tem a oportunidade de adquirir um brinquedo ou outros objetos relacionados a personagens do sucesso do momento dos cinemas, essa estratégia de venda acaba sendo atraente para os menores e até para os adultos. 


\section{SEMINÁRIO DE PESQUISA EM CIÊNCIAS HUMANAS - SEPECH \\ Humanidades, Estado e desafios didático-científicos \\ Londrina, 27 a 29 de julho de 2016}

Um dos pontos negativos é que a compra de alimentos acompanhados desses aparatos tem uma grande proporção e esses alimentos são na maioria das vezes supercalórico e açucarados, provocando vários efeitos colaterais como o ganho de peso. A mídia vem com a suposta solução para um problema que ela mesma proporcionou, e vem com o intuito de vender exercícios físicos para solucionar o sobre peso das crianças, jogos são criados onde o indivíduo precisa se movimentar, $\mathrm{CD}$ de música com letras orientando a movimentação, más na verdade tudo se resume em uma estratégia de mercado. Segundo Linn (2006, p. 131) é “(...) difícil acreditar que aconselhar as crianças a ser sobrecarregam com comerciais convencendo-as de que comida traz felicidade, as curará da obesidade e de comer excessivamente". A indústria do consumo ama culpar os pais pelos danos causados pela publicidade. É uma incumbência laboriosa para esses pais lutarem sozinhos para proteger seus filhos de sociedade do consumo que gasta milhões para manipular seu público. Isso fica mais difícil por que uma das técnicas que os profissionais do marketing utilizam é rebaixar a imagem dos pais para controlar com mais facilidade as crianças.

A solução não é acabar com tudo isso, pois tem sua alegrias, porém não pode permitir que domine as características fundamentais do brincar, ou seja, não permitir que acabe a criação espontânea, as interações da criança. Não se pode ter uma visão saudosista, porém não se pode deixar que só esse tipo de brincar reine no universo da criança e do brinquedo.

A uma necessidade da participação socialmente da criança em "situações mediadores que favoreçam o conhecimento criativo e reflexivo" (MAIA e OLIVEIRA, 2015 p. 2484). Os pais tem um significativo papel em ser o mediador nas leituras mais extensivas, orientando sobre as verdadeiras intenções da mídia e prepara-lo para a realidade. Além dos pais, os professores também torna-se uma peça de grande valor na formação do pensamento infantil lúdico, criativo e inventivo.

Há um grande número de crianças que brincam com os brindes que são oferecido pelas redes de fast food. Grande redes de alimento apostam uma grande parte de seus lucros no público infantil, investem em propagandas destinadas a crianças, além de promoções que desperta o interesse das crianças. Realizam promoções que muitas vezes o produto em si é deixado de lado em não vem em primeiro plano na hora da compra, as crianças na verdade se sentem atraídos pelos brinquedos e brincadeiras que acompanham determinados lanches, marcar de roupa e sapato entre outros. As empresas deixa em segundo plano o produto, usando os brinquedo e brincadeiras como estratégia de vendas, assim, conseguindo grandes números de consumidores mirins, além de também o público adulto que de certa forma se sentem atraído pelos objetos infantis oferecidos por várias marcas.

O investimento das indústrias no público infantil está cada vez maior. Com frequência, filmes infantis que é sucesso se torna em brinquedos e brincadeiras, roupas, tiaras, sapatos, produtos de higiene, muitas vezes, estes produtos está ligado a um alimento onde adquirindo um lanche por exemplo ele leva junto um boné, ou em relógio. Isso pode ser um pequeno exemplo no meio de tantas promoções parecidas.

Assolini (2010, p. 2) afirma que "esse tipo de estratégia é bastante utilizada também por redes de fast food como o McDonald's, que possui o McLanche Feliz, o $B o b$ 's, que tem o Trikids em seu cardápio; e o Haibb's, que oferece o Kit Habib's, todos os três produtos destinados as crianças". 


\section{SEMINÁRIO DE PESQUISA EM CIÊNCIAS HUMANAS - SEPECH \\ Humanidades, Estado e desafios didático-científicos \\ Londrina, 27 a 29 de julho de 2016}

Na grande maioria esses kits vem seguido de brinquedos que está ligado a uma coleção, que muda sempre e não economiza nas novidades, estimulando o consumidor a comprar mais e mais. Assim, as empresas lançam vários produtos, em um curto espaço, assim a criança quer sempre adquirindo determinadas marcas de alimentos para poder se sentir parte da nova sensação do momento, com isso as empresas buscam gerando "um comportamento de compra que parte do consumo constante e que prevê aquisição e descarte rápido dos itens a disposição do público infantil, contribuindo para a geração de um comportamento consumista entre os pequenos" (ASSOLINI, 2010, p.2).

Quando se trata de empresas de alimentos na divulgação dos produtos é prioridade a diversão, sendo deixado em desvantagens as informações nutricionais de tais alimentos. Essa falta de informação nutricional é um grande risco para a saúde do indivíduo, pois a maiorias dos alimentos tem grande valores calóricos, entre outros pontos negativos para a saúde do indivíduo, porém esses importantes detalhes nem sempre aparecem nas embalagens coloridas e repletas de desenhos, além de ser informações pouco relevante na hora da compra, principalmente quando a criança está chorando e apelando para o "fator amolação" para convencer os pais a comprarem. Segundo Assolini (2010, p 4):" Dados da associação Pro Teste, consumidores indica que $15 \%$ das crianças brasileiras apresentam excesso de peso, condição que aumenta o risco de doenças cardiovasculares".

Espaços de vendas como lanchonetes de grandes redes de fast food, investem em espaços para ganhar a preferência na hora da família escolher onde ir comer, ofertando lugares de recreação, reservado para o público infantil. As crianças mal come o alimento que a rede oferece, pois o que querem é ir o mais breve possível brincar no espaço oferecido, onde tem desenhos de personagens do momento, brinquedos atrativos, tudo a disposição deles, deixando de lado a comida que foi comprada. Esses tipos de espaços não ganham só a preferência dos pequenos, más também dos que os acompanham, que de certa forma tem mais tranquilidade para comer e conversar enquanto as crianças brincam. Espaços assim pretendem ganham a preferência na escolha oferecendo alimentos e um certo tipo de babá para as crianças, além de diversão, agradando os pais e os filhos, porém aumentando cada vez mais a distância entre pais e filhos, abrindo lugar para a indústria cultural trabalhar na formação do pensamento infantil.

Redes como Bob 's, McDonald's e Habib's, são grandes exemplos do que denomina-se o brincar fast food, com promoções como McLanche Feliz, Kit Habib's Trikids, que oferecem um espaço para as crianças se "divertirem", além de brindes que acompanham seus lanches e porções. Cada novo filme é feito uma nova promoção é lançada, sempre inovando suas táticas de vendas, para garantir o consumo visando o lucro.

\section{CONSIDERAÇÕES FINAIS}

Diante disso, podemos inferir que o ato de brincar, no cenário da cultura capitalista, está cada vez mais sufocado pelo ato de "ter" a posse de um brinquedo/mercadoria, os conceitos de brincar e brincadeiras estão sendo alterados por leituras distorcidas à luz do consumo e da produção. Essas empresas em nome do lucro fazem o que for preciso para conseguir seus clientes, movimentando milhões em 


\section{SEMINÁRIO DE PESQUISA EM CIÊNCIAS HUMANAS - SEPECH \\ Humanidades, Estado e desafios didático-científicos \\ Londrina, 27 a 29 de julho de 2016}

dinheiros por todos os países. Quanto mais consumidores melhor para o sistema vigente. Enquanto isso, nossa criança pequena se vê rodeada desses fetiches de mercado e, sendo "expulsas" do jardim da infância, com seus brincares espontâneos, criativos, expressivos e inventivos.

As empresas de roupas e calçados não querem ficar para trás na corrida pela atenção da criança, grande é o número de marcas que lançam roupas e calçados com estampas de personagens como a Barbie e Frozen, super-heróis, ou vem acompanhados de relógios, tiaras e entre outros objetos que despertam o desejo de ter nas crianças. A criança em sua compra quer primeiro o brinde e embalagem e, por último o produto, tendo consciência dessa realidade as empresas de publicidade não medem esforços e investem muito em personagens como brindes e embalagens.

Essa técnica de venda não visa alimentar as pessoas, mais sim vender mais, aumentar os lucros. O público infantil recebe uma avalanche de marketing de alimentos acompanhado por uma publicidade de brinquedos. A indústria Cultural quer isso, vender, lucrar, transformar até as brincadeiras em produtos usados para aumentar o consumo. O lucro é seu objetivo, e o conforto e a facilidade que dá aos pais facilita essas ações que nem sempre é benéfica ao indivíduo.

Pais e filhos são manipulados o tempo todo, até mesmo na hora de comer e não percebem, a escola que deveria ajudar a criar um senso crítico nas crianças acabam reforçando o que as grandes redes de fast food com a ajuda da mídia e do cinema, ditam com gostoso e diversão. Quando as empresas oferecem vários brinquedos ligados a personagem da televisão para estimular o indivíduo a comprar, além de induzir o consumismo transforma também o brincar em mercadoria, a criança não deseja brincar, se divertir, ela quer ter um determinado brinquedo que talvez todos seus colegas tem, consequentemente perdendo o valor das brincadeiras, de imaginar, de criar uma história para um determinado brinquedo, de imaginar e criar um cenário pois já vem tudo determinado pela mídia, não dando espaço para a criança exercer seu direito de criatividade, mais sim formando fieis consumidores.

A partir dos estudos realizados para realização do presente trabalho percebe-se que o consumo tomou conta da vida das pessoas, as crianças que são um público fácil é muito atingida pela entretenimento, pode-se dizer que esse entretenimento tomou conta da vida dos indivíduos. Crianças e pais vão sendo manipulados pela mídia e não tem consciência de tal ato, os pais não sabem que quando sedem e compram um lanche que vem acompanhada de produtos de personagens licenciados estão a verdade garantindo os futuros consumidores. Diante disso, a família e os espaços formativos escolares devem possibilitar experiências lúdicas com brincares espontâneos e criativos, sem necessariamente estar restrito ao objeto e a mercadoria.

\section{REFERÊNCIAS}

ADORNO, Theodor W. A arte é alegre? In: RAMOS-DE-OLIVEIRA, Newton; ZUIN, Antônio Álvaro Soares; PUCCI, Bruno (Orgs.). Teoria crítica, estética educação. Campinas: Unimep, 2001. p. 11-18. 


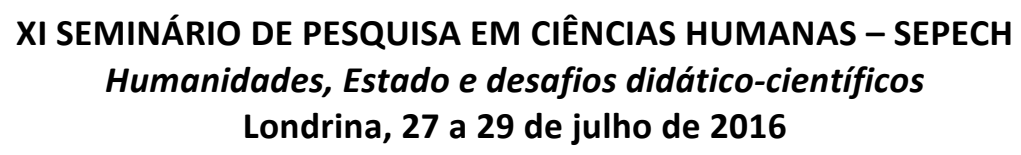

ADORNO, Theodor W.; HORKHEIMER, Max. Dialética do esclarecimento: fragmentos filosóficos. Trad. Guido A. de Almeida. Rio de Janeiro: J. Zahar, 1985. GROPPO, Luíz Antonio. MARTINS, Marcos Francisco. Introdução a pesquisa em educação. $2^{\circ}$ ed. Piracicaba, SP: Biscalchin, 2007.

LINN, Susan. Crianças do Consumo: a infância Roubada. Tradução Cristiana Tognelli. São Paulo: Instituto Alana. 2006

LUDKE, Menga e ANDRÈ, Marli. E. D. A. Pesquisa em educação abordagens qualitativas. São Paulo: EPU, 1986.

OLIVEIRA, Marta Regina Furlan. A infância do consumo e a expropriação do pensamento criativo e inventivo. XI Congresso nacional de educação. PR: Curitiba, 2013.

OLIVEIRA, Marta Regina Furlan. MAIA, Daiane de Jesus. A infância do consumo e a expropriação do pensamento criativo e inventivo. XVI Semana da educação, VI Simpósio de pesquisa e pós graduação em educação. Paraná. 2014.

ASSOLINI, Pablo José. O mundo encantdo das redes de fast food. Disponivel em: http://www2.metodista.br/unesco/1_Ecom\%202010/Arquivos/Trabalhos/27O\%20mundo\%20encantado\%20das\%20redes\%20de\%20fast $\% 20$ food PabloAssolini.pd f $>$ Acesso em 19 Fev. 2016 